\title{
Characterization of the Triplet State of Tris(8-hydroxyquinoline)aluminium(III) in Benzene Solution
}

\author{
Hugh D. Burrows, ${ }^{*}{ }^{\dagger}$ Mariana Fernandes,${ }^{\dagger}$ J. Seixas de Melo, ${ }^{\dagger}$ Andrew P. Monkman, ${ }^{\ddagger}$ and \\ Suppiah Navaratnam $\S$ \\ Departamento de Química, Universidade de Coimbra, P3004-535 Coimbra, Portugal, Department of Physics, \\ University of Durham, Durham DH1 3LE, UK, FRRF, Daresbury Laboratory, Warrington, WA4 4AD, UK, and \\ Biosciences Research Institute, University of Salford, M4 4WT, UK
}

Received July 14, 2003; E-mail: burrows@ci.uc.pt

Since Tang and VanSlyke first reported efficient electroluminescence from a device based on tris(8-hydroxyquinoline)aluminium(III) $\left(\mathrm{Alq}_{3}\right)$ as the luminescent layer, ${ }^{1}$ organic light-emitting diodes (OLEDs), based on these materials, are now at the stage where they are being used as monochrome displays. This results from emission from a ligand centered $\pi, \pi^{*}$ excited state, formed in the transition of an electron from a highest occupied molecular orbital (MO) lying mainly on the phenoxide ring to a lowest unoccupied MO predominantly on the nitrogen atom. ${ }^{2}$ By doping with the appropriate dyes, the emission can be tuned through the visible spectrum, ${ }^{3,4}$ leading to the possibility of full color OLED displays. The basic processes involved are reasonably well understood, 5,6 with electroluminescence involving generation of singlet excitons from electron-hole recombination. From spin statistics, theoretical calculations, and experiment, ${ }^{7}$ the singlet:triplet exciton ratio is $1: 3$, limiting the maximum internal OLED efficiency from fluorescent materials to $\leq 25 \%$. Nevertheless, by doping with heavy atom-containing complexes, such as platinum(II) octaethylporphyrin (PtOEP), it is possible to capture triplet excitons (or charge carriers) to give electrophosphorescence, increasing internal quantum yields dramatically. ${ }^{8}$ Although of interest for display applications, efficient exploitation requires detailed knowledge of the properties of the lowest triplet state of $\mathrm{Alq}_{3}$, which is not available. We are reporting here what we believe to be the first detailed characterization of this state.

There is relatively little detailed information on $\mathrm{Alq}_{3}$ photophysics. Various values have been reported for the fluorescence quantum yield $^{3,9,10}$ and lifetime, ${ }^{3,11}$ and only indirect information exists on the triplet state. ${ }^{12,13}$ Attempts to observe phosphorescence have proved unsuccessful, ${ }^{11,12}$ although some information has been inferred from data on heavy metal quinolates. ${ }^{11} \mathrm{We}$ have shown ${ }^{14}$ that pulse radiolysis of benzene solutions selectively produces triplet states of conjugated organic polymers by energy transfer from appropriate sensitizers following pulse radiolysis of benzene solutions. The triplet state of $\mathrm{Alq}_{3}$ is characterized in the same way.

Following pulse radiolysis ${ }^{15}$ of an Ar saturated solution of $\mathrm{Alq}_{3}$ $\left(2.25 \times 10^{-4} \mathrm{M}\right)$ and biphenyl $(0.01 \mathrm{M})$ in benzene, the absorption of the biphenyl triplet state ${ }^{16}$ was observed, with a maximum below $380 \mathrm{~nm}$. This decayed within a few microseconds to be replaced by a new absorption maximum around $510 \mathrm{~nm}$ (Figure 1). This is similar to spectra reported by Ballardini et al. ${ }^{11}$ for triplet states of various heavy metal 8-quinolinol chelates and is assigned to the $\mathrm{Alq}_{3}$ triplet state, which decayed by good first-order kinetics with a lifetime $\tau=56.3 \pm 0.4 \mu \mathrm{s}$. From the analysis of transient diffusion measurements in doped films, ${ }^{12}$ a lifetime of $25 \pm 15 \mu$ s was

\footnotetext{
$\dagger$ Universidade de Coimbra
University of Durham.

§ Daresbury Laboratory and University of Salford.
}

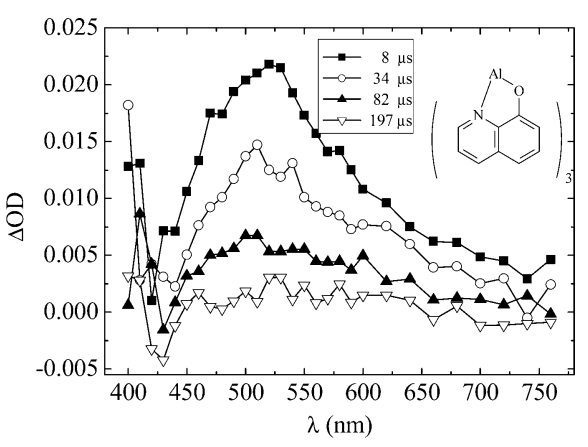

Figure 1. Spectra observed after pulse radiolysis of argon saturated solutions of $\mathrm{Alq}_{3}\left(2.25 \times 10^{-4} \mathrm{M}\right)$ and biphenyl $(0.01 \mathrm{M})$ in benzene.

estimated for this triplet state. In contrast, a value of ca. $10 \mathrm{~ms}$ was reported from delayed luminescence measurements on polycrystalline $\mathrm{Alq}_{3}$ at $6 \mathrm{~K} .{ }^{13}$ This may indicate a marked temperature dependence for the triplet decay, possibly due to triplet hopping to quenching sites at higher temperatures. From the initial absorbances of biphenyl triplet and $\mathrm{Alq}_{3}$ transient absorptions, and the value $\epsilon$ $=27100 \mathrm{M}^{-1} \mathrm{~cm}^{-1}$ for the biphenyl triplet state, ${ }^{16}$ a molar absorption coefficient $\epsilon_{510 \mathrm{~nm}}=3350 \pm 350 \mathrm{M}^{-1} \mathrm{~cm}^{-1}$ was determined for the $\mathrm{Alq}_{3}$ triplet state, within the range of values reported for triplets of heavy metal quinolates. ${ }^{11}$ The triplet state was also studied by laser flash photolysis, exciting an Ar saturated solution of $\mathrm{Alq}_{3}\left(6.7 \times 10^{-5} \mathrm{M}\right)$ in benzene with the third harmonic of a Nd:YAG laser $(355 \mathrm{~nm})$. A weak band was observed around $510 \mathrm{~nm}$, in addition to ground-state depletion at $400 \mathrm{~nm}$. This decayed within ca. $100 \mu \mathrm{s}$. Using the benzophenone triplet state in benzene as an actinometer, ${ }^{17}$ the molar absorption coefficient of $\mathrm{Alq}_{3}$ determined by pulse radiolysis, and the initial triplet absorbances of the two compounds, we determined the triplet quantum yield, $\phi_{\mathrm{T}}=0.19_{5}$.

The $\mathrm{Alq}_{3}$ transient absorption at $510 \mathrm{~nm}$ decayed faster in the presence of oxygen, in agreement with assignment to a triplet state. This quenching by molecular oxygen is expected to involve the Type II energy transfer reaction ${ }^{18}$

$$
{ }^{3} \mathrm{Alq}_{3} *+\mathrm{O}_{2}\left({ }^{3} \Sigma_{\mathrm{g}}{ }^{-}\right) \rightarrow \mathrm{Alq}_{3}+\mathrm{O}_{2} *\left({ }^{1} \Delta_{\mathrm{g}}\right)
$$

to produce singlet oxygen. Direct observation of singlet oxygen phosphorescence at $1270 \mathrm{~nm}$ following excitation of aerated solutions at $355 \mathrm{~nm}$ provided evidence for this. Singlet oxygen luminescence as a function of laser intensity, using $1 \mathrm{H}$-phenalen1-one as a standard, ${ }^{19}$ gave a quantum yield $\phi_{\Delta}=0.275$. Within experimental uncertainty, this is in reasonable agreement with the yield of triplet state formation, as expected from the above reaction. From these two values, we suggest $\Phi_{\mathrm{T}}=0.24$ with an error of 


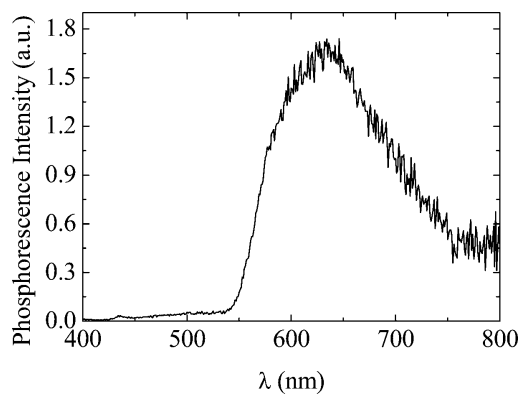

Figure 2. Phosphorescence spectra observed upon excitation at $393 \mathrm{~nm}$ of $\mathrm{Alq}_{3}$ in an ethyl iodide glass.

$\pm 25 \%$. This is close to $\phi_{\mathrm{T}} \approx 0.25$ estimated for the meridianal isomer at low temperatures. ${ }^{13}$ This, coupled with the fluorescence yield, ${ }^{3,9,10}$ shows the importance of nonradiative decay of singlet excitons in $\mathrm{Alq}_{3}$, with internal conversion being particularly important. $^{20}$

Energy transfer is a valuable method for determining triplet energies. ${ }^{14,21}$ Various sensitizers were used to transfer triplet energy to $\mathrm{Alq}_{3}$ on pulse radiolysis of Ar saturated benzene solutions. Efficient sensitization occurred with 9-fluorenone $\left(E_{\text {triplet }}=2.19\right.$ $\left.\mathrm{eV} ; 1 \mathrm{eV}=96.488 \mathrm{~kJ} \mathrm{~mol}^{-1}\right),{ }^{22}$ while none was observed with acridine $\left(E_{\text {triplet }}=1.97 \mathrm{eV}\right) .{ }^{22}$ With pyrene $\left(E_{\text {triplet }}=2.10 \mathrm{eV}\right),{ }^{22}$ some energy transfer occurs, but the rate of decay of the $\mathrm{Alq}_{3}$ triplet state is slower than with the other sensitizers, suggesting equilibrium with the pyrene triplet and, hence, very similar energies. We thus give the triplet energy of $\mathrm{Alq}_{3}$ in benzene as $2.10 \pm 0.05 \mathrm{eV}$. This is close to the value of ca. $2.0 \mathrm{eV}$ estimated by Baldo et al. ${ }^{12}$ and the value of $2.13 \mathrm{eV}$ reported by Martin et al. from time-dependent density-functional theory calculations. ${ }^{23}$ The phosphorescence of $\mathrm{Alq}_{3}$ was studied in an ethyl iodide glass at $77 \mathrm{~K} .{ }^{24}$ The presence of the heavy atom iodine is expected to promote intersystem crossing. A broad band emission was observed, with a maximum at $660 \mathrm{~nm}$ (Figure 2), and is assigned to $\mathrm{Alq}_{3}$ phosphorescence. From the spectrum, a triplet energy of $2.17 \pm 0.10 \mathrm{eV}$ was estimated, in agreement with the energy transfer value. The lifetime is short and at the limit of our detection system $(\leq 50 \mu \mathrm{s})$, which may explain why this emission has previously proved elusive. However, this is consistent with the lifetime determined by pulse radiolysis. Similar phosphorescence is also observed in a benzene glass sensitized by benzophenone (see Supporting Information).

Electrophosphorescence in doped $\mathrm{Alq}_{3}$ systems could arise from Dexter energy transfer. ${ }^{8,25}$ To test this, triplet-triplet energy transfer from $\mathrm{Alq}_{3}$ to PtOEP was studied. Following pulse radiolysis of $\mathrm{Ar}$ saturated benzene solutions of biphenyl $(10 \mathrm{mM}), \mathrm{Alq}_{3}(20-100$ $\mu \mathrm{M})$, and PtOEP $(1-10 \mu \mathrm{M})$, the initial absorption of the $\mathrm{Alq}_{3}$ triplet state at $510 \mathrm{~nm}$ decayed more rapidly, to be replaced by the PtOEP triplet state absorption at $410 \mathrm{~nm}$. Bleaching of the porphyrin absorption around $540 \mathrm{~nm}$ also occurred. These results confirm the triplet energy transfer reaction to the lower energy $\left(E_{\mathrm{T}}=1.92 \mathrm{eV}\right)$ porphyrin, presumably by the Dexter transfer mechanism

$$
{ }^{3} \mathrm{Alq}_{3} *+\mathrm{PtOEP} \rightarrow \mathrm{Alq}_{3}+{ }^{3} \mathrm{PtOEP} *
$$

A rate constant $k=3.9 \times 10^{9} \mathrm{M}^{-1} \mathrm{~s}^{-1}$, within the range typically observed for triplet - triplet energy transfer, was estimated from the grow-in of porphyrin triplet absorption as a function of concentra- tion. This agrees with some electrophosphorescence in $\mathrm{Alq}_{3}$ devices resulting from Dexter transfer to dopant. ${ }^{8,25}$ Yet the short lifetime of the $\mathrm{Alq}_{3}$ triplet state and the relatively modest energy transfer rate suggest that, as with conjugated polymer devices containing this dopant, ${ }^{26,27}$ charge trapping by PtOEP may also be important.

Acknowledgment. Pulse radiolysis experiments were carried out at the Free Radical Research Facility, Synchrotron Radiation Department, CLRC Daresbury Laboratory, Warrington, UK, with the support of the European Commission through the "Improving Human Potential" Transnational Access to Major Research Infrastructures HPRI-CT-2002-00183. We are also grateful to a referee for suggesting studying phosphorescence in ethyl iodide, and to POCTI, FCT, FEDER, and the Royal Society for further funding, and the Leverhulme Trust for a Fellowship (A.P.M.).

Supporting Information Available: Experimental details (PDF). This material is available free of charge via the Internet at http:// pubs.acs.org.

\section{References}

(1) Tang, C. W.; VanSlyke, S. A. Appl. Phys. Lett. 1987, 51, 913-915.

(2) Curioni, A.; Boero, M.; Andreoni, W. Chem. Phys. Lett. 1998, 294, $263-$ 271.

(3) Tang, C. W.; VanSlyke, S. A.; Chen, C. H. J. Appl. Phys. 1989, 65, 36103616 .

(4) Burrows, P. E.; Gu, G.; Bulovic, V.; Shen, Z.; Forrest, S. R.; Thompson, M. E. IEEE Trans. Electron Devices 1997, 44, 1188-1203.

(5) Salbeck, J. Ber. Bunsen-Ges. Phys. Chem. Chem. Phys. 1996, 100, 16671677.

(6) Friend, R. H.; Gymer, R. W.; Holmes, A. B.; Burroughes, J. H.; Marks, R. N.; Taliani, C.; Bradley, D. D. C.; Dos Santos, D. A.; Bredas, J. L.; Logdlund, M.; Salaneck, W. R. Nature 1999, 397, 121-128.

(7) Baldo, M. A.; O'Brien, D. F.; Thompson, M. E.; Forrest, S. R. Phys. Rev. B 1999, 60, 14422-14428.

(8) Baldo, M. A.; O'Brien, D. F.; You, Y.; Shoustikov, A.; Sibley, S.; Thompson, M. E.; Forrest, S. R. Nature 1998, 395, 151-154.

(9) Lytle, F. E.; Storey, D. R.; Juricich, M. E. Spectrochim. Acta, Part A 1973, 29, 1357-1369.

(10) Garbuzov, D. Z.; Bulovic, V.; Burrows, P. E.; Forrest, S. R. Chem. Phys. Lett. 1996, 249, 433-437.

(11) Ballardini, R.; Varani, G.; Indelli, M. T.; Scandola, F. Inorg. Chem. 1986, $25,3858-3865$.

(12) Baldo, M. A.; Forrest, S. R. Phys. Rev. B 2000, 62, 10958-10966.

(13) Braun, M.; Gmeiner, J.; Tzolov, M.; Coelle, M.; Meyer, F. D.; Milius, W.; Hillebrecht, H.; Wendland, O.; von Schutz, J. U.; Brutting, W. J. Chem. Phys. 2001, 114, 9625-9632

(14) Monkman, A. P.; Burrows, H. D.; Hartwell, L. J.; Horsburgh, L. E.; Hamblett, I.; Navaratnam, S. Phys. Rev. Lett. 2001, 86, 1358-1361.

(15) Pulse radiolysis experiments were carried out using high energy electron pulses from a $12 \mathrm{MeV}$ linear accelerator at Daresbury Laboratories, as described in detail in the Supporting Information.

(16) Bensasson, R. V.; Land, E. J. Trans. Faraday Soc. 1971, 67, 1904-1915.

(17) Carmichael, I.; Hug, G. L. J. Phys. Chem. Ref. Data 1986, 15, 1-250.

(18) Bensasson, R. V.; Land, E. J. Excited States and Free Radicals in Biology and Medicine; Oxford University Press: Oxford, 1993.

(19) Oliveros, E.; Suardimurasecco, P.; Aminiansaghafi, T.; Braun, A. M.; Hansen, H. J. Helv. Chim. Acta 1991, 74, 79-90.

(20) Using the value $\phi_{\mathrm{F}}=0.32$ from ref 10 and the above value gives $\phi_{\mathrm{IC}} \approx$ 0.45 .

(21) Monkman, A. P.; Burrows, H. D. In Light Emitting Polymers; Shinar, J., Sheats, J., Eds.; Wiley: New York, 2003.

(22) Murov, S.; Charmichael, I.; Hug, G. L. Handbook of Photochemistry; M Dekker, Inc.: New York, 1993.

(23) Martin, R. L.; Kress, J. D.; Campbell, I. H.; Smith, D. L. Phys. Rev. B 2000, 61, 15804-15811.

(24) Phosphorescence measurements were made in glasses at $77 \mathrm{~K}$ using a Spex 1934D phosphorimeter accessory with a Fluorolog 3-22 instrument

(25) Thompson, M. E.; Burrows, P. E.; Forrest, S. R. Curr. Opin. Solid State Mater. Sci. 1999, 4, 369-372.

(26) Lane, P. A.; Palilis, L. C.; O'Brien, D. F.; Giebeler, C.; Cadby, A. J.; Lidzey, D. G.; Campbell, A. J.; Blau, W.; Bradley, D. D. C. Phys. Rev. $B$ 2001, 63, 235206.

(27) Cleave, V.; Yahioglu, G.; Le Barny, P.; Hwang, D. H.; Holmes, A. B.; Friend, R. H.; Tessler, N. Adv. Mater. 2001, 13, 44-47.

JA037254F 